\title{
Study on the edge space composition of urban living block and the renewal of old city__ A case study of the Deshengqiao historic block
}

\author{
Xia Zhihao ${ }^{1}$ \\ ${ }^{1}$ School of civil engineering and architecture Wuhan University of Technology, Wuhan, Hubei Province, China
}

\begin{abstract}
The reconstruction of historic district is a hot topic in urban design in recent years. Weighing the interests of all parties, improving the space quality and meeting the use needs has become a century problem. In this paper, the Deshengqiao historic block is taken as an example to investigate by observing and recording the form of the inside and outside of the street and the edge space, people's behavior state, so that we can explore the use and future development of the edge space. According to the demand of the Deshengqiao residents who "want people to come in", this paper puts forward a solution to present the Deshengqiao bolck's most characteristic and life-rich articles and buildings in an artistic form, so as to create an attractive Street entrance and a comfortable communication place and spiritual space,enhancing the image of the city and giving play to the functions of edge spaces.
\end{abstract}

\section{Introduction}

\subsection{The edge space}

Since the 1990s, with the rapid development of urbanization in Wuhan, Tanhualin commercial street, river beach, Yellow Crane Tower Scenic Area and other urban areas have risen rapidly. However, part of the blocks, as a residential area, is gradually declining due to the slow renewal and serious aging of infrastructure, becoming an "isolated island" in the city. The edge space between the new commercial interface and the original residential area has become an important node due to the complexity and diversity of users and space interfaces in urban design[1].

Kevin Lynch regards the edge as an important form of the five elements of urban imago. He believes that the edge can separate an area from other areas, and also connect the relevant areas on both sides of the line[2].Christopher Alexander summed up the experience of boundary effect and boundary area in public space in "Pattern Language": "if the boundary no longer exists, then the space will never be alive[3-4]."

In a broad sense, the separation zone between the city and town, the public crisscross zone between the construction units, the water system, streets, and verandas all belong to the edge spaces. All levels of the edge spaces throughout the city connect different functional areas, spaces and activities, forming an orderly urban space system[5]. For the Deshengqiao historic block, the edge spaces are endowed with more functions and significance. It not only carries the life of the inhabitants, but also has many new business and tourism functions. It's a connection to several different "worlds".

\subsection{The form of the edge space and the opening degree of the block}

How to get along with multiple worlds? Hu Kai, a Chinese scholar, pointed out an important conclusion in his research on the relationship between human activities and interface in edge spaces of historical blocks: with the evolution of time, the block's acceptability of the outside world has gradually changed. Different blocks have different acceptability to life outside the block leading to different forms of the edge spaces[1]. (Figure 1)
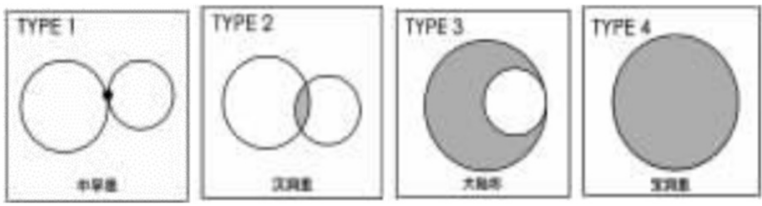

Fig. 1. Four different forms of edge space

\subsection{The edge space and urban renewal}

Residents in historical districts have different acceptability degrees for new things, which will affect the intensity and means of the urban design intervention.

Urban acupuncture, proposed by Morales in 1982, is an urban renewal model of small-scale reconstruction. It carries out small-scale reconstruction by "point-cutting" in a specific area, so as to trigger the change of its surrounding environment, and finally stimulate the vitality of the city, change the appearance of the city [6]

* Corresponding author: 2572391238@qq.com 
Compared with large-scale demolition and reconstruction, this mode avoids the problems such as high cost and difficult expropriation difficulties, and minimizes the damage to the memory of urban context and the inner feelings of residents, finding a balance between the protection of urban fabric, the continuation of historical context and urban development.
The Deshengqiao block is a thousand-year old street. Located to the north of the Yellow Crane Tower, Wuchang District, Wuhan City, Hubei Province, and to the west of the Hubei Wuchang Experimental Middle School and the Fenghuang Mountain, it is a landmark of the old city of Wuchang. Affected by profound historical and cultural accumulation and complex evolution history, Deshengqiao living block has formed rich street texture and spatial form [7-8].

\section{Subjects}

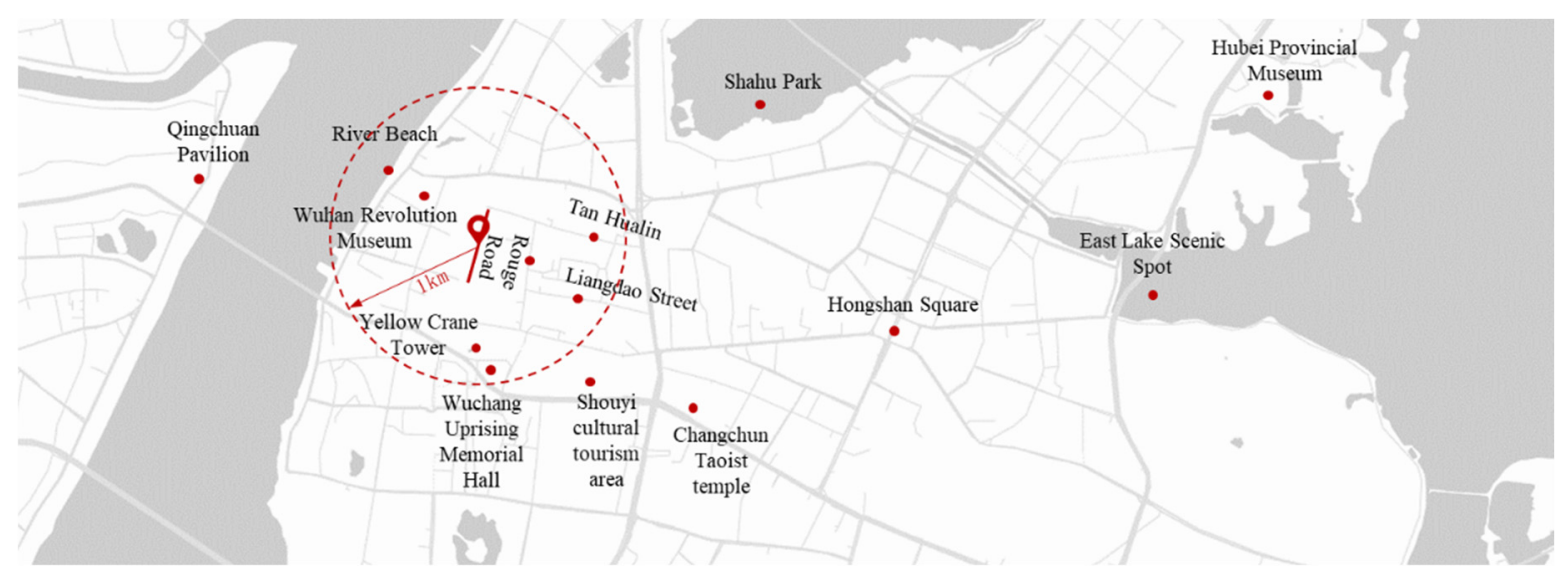

Fig. 2. Location Analysis of the Deshengqiao block.

\subsection{The spatial pattern of "chaos is order"}

- Location and transportation: With convenient transportation and surrounded by scenic spots and business circles, it is the regional center of Wuchang District and even Wuhan City. Within a walking range of $1 \mathrm{~km}$, you can reach River Beach, Yellow Crane Tower, Wuchang Uprising Memorial Hall and other scenic spots. (Figure 2)

- Economic development: the rent and prices here are relatively low. There are a lot of traditional handicraft industry and business - based self-employed households.

- Population type: Except for the students and their families of the No. 14 Middle School temporarily rented here, the residents here are mostly natives. Most of them are low-income people who live on self-run stalls. Their status in cities is as edgeized as the environment they live in.

- Living space: It is lively and fresh here. Electric vehicles, bicycles parked at random on the roadside, washing clothes in the street window drying, selling vegetables, begging sound in the ear. Sunscreen curtains in the pedestrian street above, retail vegetables placed on the street, blurred the boundaries of the street. There is no monitoring and no urban manager to punish encroachment on public space. Here, has the Wuchang old city unique temperament.

- Built environment: Old and dilapidated, it hides the memory of a time. Just a few steps away, you can enjoy the old houses with a history of over a hundred years, and find an old neighbor to chat with. The history of Wuchang is on your side. The limited space has been self-built to meet its own reasonable needs, so that the old and new buildings blend with each other. Here, brick by brick, are the epitome of the history of the old Wuchang city.

- Public facilities. Here is different from the outer urban space, the internal facilities are obsolete, lack of greenery, lack of open space, lack of parking, lack of privacy, lack of spiritual places that residents need. The narrow entrance makes it difficult for tourists to reach the business district.

\subsection{The connection of " $\mathrm{N}$ worlds"}

The Deshengqiao block seems incompatible with the surrounding environment. At the end of the Deshengqiao block, the residential area and the Yellow Crane Tower face each other. Both of them have experienced many vicissitudes of life, but the city position is very different. The Yellow Crane Tower has retained its original shape and structure after transformation. It is classic and clean and bright, and its plan form is simple and broad. On the basis of historical buildings, the commercial street of Tanhualin presents the appearance of scale and form under the standard design language, which is "controlled", "unified", "reasonable" and "suitable for opening and closing". The Deshengqiao residential block has a historical evolution process of self-reconstruction, forming a high-density pattern.

The author makes a comparison of the general layout of these three places, as shown in Table 1. 
Table 1. A comparison of "N worlds"

\begin{tabular}{|l|l|l|}
\hline The Yellow Crane Tower Scenic & The Deshengqiao block \\
Spot
\end{tabular}

\section{Methods}

\subsection{The outer edge space and the openness of block}

The edge space form adopts the observation record method. The residents' acceptability of the opening of the block adopts the method of questionnaire, and the respondents are residents in the Deshengqiao area. The survey content mainly includes the following three parts: population identity (including gender, age, occupation, which is a single choice), preference for openness (single choice) and reasons (multiple choice). Within 2 days, a total of 42 questionnaires were sent out and all of them were recalled, with 40 valid questionnaires. Among them, 5 are teenagers, 24 are the middle-aged, and 11 are the elderly.

\subsection{The interior edge Space and the vibrancy of the block}

The author chooses three representative edge Spaces in the interior for observation, and evaluates the vitality of the block from the two dimensions of vitality representation and vitality composition. Representation of vitality refers to people's activities, including the number of people, type of activities, residence time, etc., while composition of vitality refers to the surrounding physical environment, including location (accessibility and visibility), safety, scale, function, spatial relationship, visual diversity, activities and rest facilities, landscape greening, etc.

\subsection{The edge space reconstruction and the urban renewal}

On the basis of step one and step two, through spatial syntax analysis, combined with some cases, based on the local characteristic products of the Deshengqiao block, design the edge space at the important nodes to effectively improve the quality of internal space.

\section{Results \& Discussion}

\subsection{The outer edge space and the openness of block}

Through the survey, we found that most of the residents are middle-aged and elderly, and most of their occupations are self-employed and blue collar. In this situation, most people are willing that let external visitors enter the block and consume to increase their revenue. Retired people also like to see and communicate with external young people. Only a small number of residents worry about privacy, congestion and other issues. (Figure 3)

However, the existing entrance has an iron gate, and the dilapidated environment makes it look bad. Tourists rarely stop to enter, except for nearby residents who are attracted by the low prices. (Table 2) 


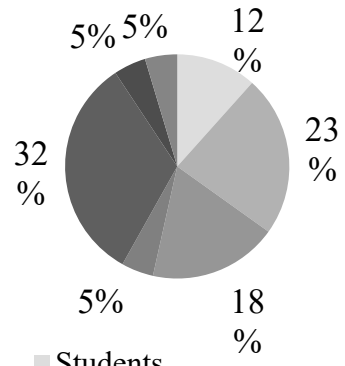

Students

the self-employed

- blue-collar workersrs

चhite collar workers

- the Retired elderly

- housewife

mothers

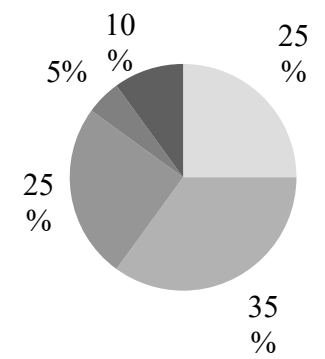

open

चvers open

normal

घers closed

a closed

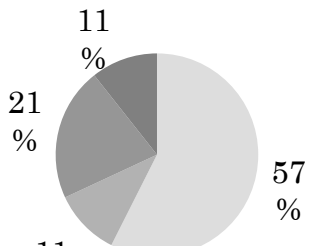

11

$\%$

It can drive the economy and increase the income

More young people can be seen to inject vitality into the block

Enrich the business form

\section{Promote the improvement of municipal and public facilities}

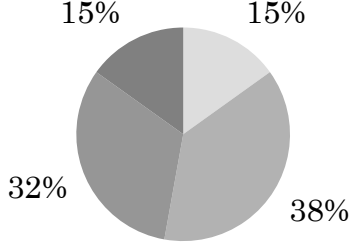

The low level of development here declines the appearance of the city

It is difficult to protect the privacy of residents
- Traffic congestion, and even bring security risks

Fig. 3. Survey on the acceptability of the crowd to the openness of the block

Table 2. Comparison of three edge spaces

\begin{tabular}{|c|c|c|c|}
\hline & The entrance 1 & The entrance 2 & The entrance 3 \\
\hline \multirow[t]{2}{*}{ position } & 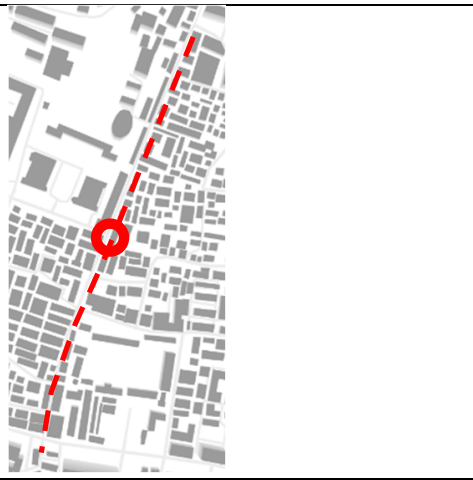 & 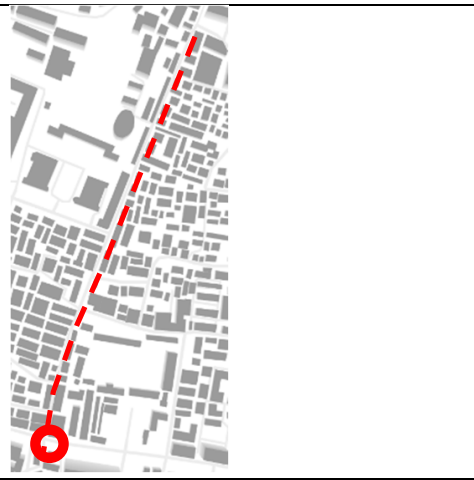 & 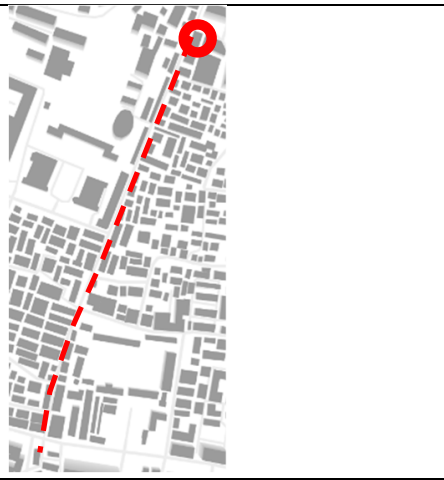 \\
\hline & $\begin{array}{l}\text { Intersection of the Huoju road and } \\
\text { the Deshengqiao street }\end{array}$ & $\begin{array}{l}\text { Intersection of the Zhonghua road } \\
\text { and the Deshengqiao street }\end{array}$ & $\begin{array}{l}\text { Intersection of the Tanhualin } \\
\text { street and the Deshengqiao street }\end{array}$ \\
\hline \multirow[t]{2}{*}{$\begin{array}{l}\text { Spatial } \\
\text { characteris } \\
\text { tics }\end{array}$} & -4 ramar & & \\
\hline & $\begin{array}{l}\text { Pedestrian T-junction. There are } \\
\text { many vendors here. The goods are } \\
\text { placed along the street. It is very } \\
\text { lively and open. }\end{array}$ & $\begin{array}{l}\text { Due to the upcoming demolition, it } \\
\text { is relatively depressed here. The bin } \\
\text { are placed at the intersection, and the } \\
\text { appearance is poor. The degree of } \\
\text { openness is medium. }\end{array}$ & $\begin{array}{l}\text { The intersection is under } \\
\text { construction. There is only a } \\
\text { narrow and winding corridor. The } \\
\text { degree of openness is medium. }\end{array}$ \\
\hline $\begin{array}{l}\text { Personnel } \\
\text { activities }\end{array}$ & \multicolumn{2}{|c|}{$\begin{array}{l}\text { Most of the people who enter here are local residents, because the price of } \\
\text { food here is cheaper and the department stores are rich and concentrated. } \\
\text { Seeing that the building at the entrance is relatively dilapidated, passengers } \\
\text { are reluctant to enter. The edge space has neither attraction nor residence. } \\
\text { The current prosperity depends on people's living needs such as buying } \\
\text { vegetables. }\end{array}$} & $\begin{array}{l}\text { Most tourists from the Tanhualin } \\
\text { street stop here. The reasons are as } \\
\text { follows: } \\
\text { - The landscape image here is } \\
\text { poor. Live poultry and seafood are } \\
\text { being killed and sold in the } \\
\text { vegetable market, which look and }\end{array}$ \\
\hline
\end{tabular}




\begin{tabular}{|l|l|l|}
\hline & & $\begin{array}{l}\text { smell bad. } \\
\text { - The business format does not } \\
\text { meet the needs of visitors. Visitors } \\
\text { need dining, entertainment and } \\
\text { socializing, but cheap vegetable } \\
\text { stands and daily groceries are the } \\
\text { majority here. }\end{array}$ \\
\hline
\end{tabular}

\subsection{The interior edge Space and the vibrancy of the block}

The behaviors of walking users in the block were divided into three categories according to different nature:

- Necessary activities: shopping for food., fetching water, drying clothes, eating, etc.

- Spontaneous activities: sunbathing, reading newspapers, etc.

- Social activities: chatting, playing cards, playing chess, children's games, dancing, etc.

\subsubsection{Vegetable market: a dense place with no residence}

Vegetable market is located in the Deshengqiao main street, along the street for food stalls, restaurants and other individual businesses.(Figure.4)

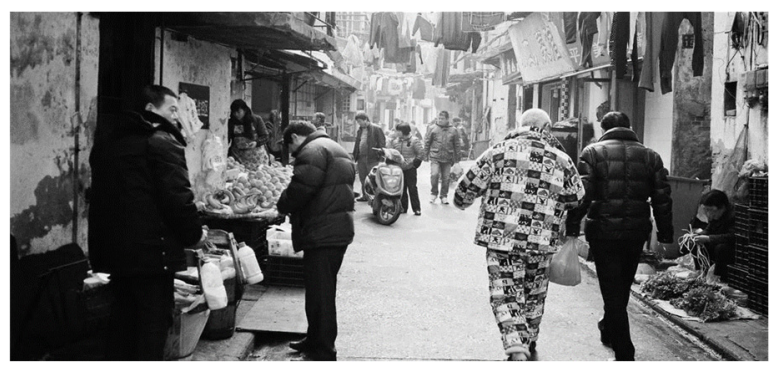

Fig.4. The vegetable market

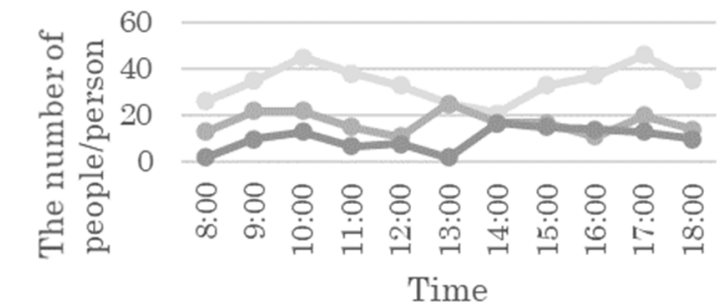

- Necessary activity $\longrightarrow$ Social activity
- Spontaneous activity

Fig.5. Characterization of vegetable market vitality

Here, the active subjects are diverse. The group activities are mainly necessary activities such as shopping for food and passing by, and the length of stay is short. In the process of meeting people, there will be short social activities such as chatting. Occasional shopping and other spontaneous activities. (Figure 5)

This is a first-level street in the area, with strong accessibility and high gathering effect, and it is also the area with the most intense worldliness. Traffic here is crowded, the width of the street is about 7 meters, motor vehicles, non-motor vehicles, pedestrians mixed. It is almost an inevitable route for commuters in the neighborhood. There is a strong commercial atmosphere and rich forms of business. Sunshades, trees and even front steps provide a rich spatial hierarchy. A variety of shop signs, potted plants, drying clothes, external goods look rich and disorderly. Heavy traffic and lack of recreational facilities make it difficult for people to stay.

\subsubsection{Teahouse and chess \& card room: a social place with normal quality and fixed group}

The teahouse is located in the secondary street of the Deshengqiao district, which is the junction of commercial and residential areas. (Figure 6)

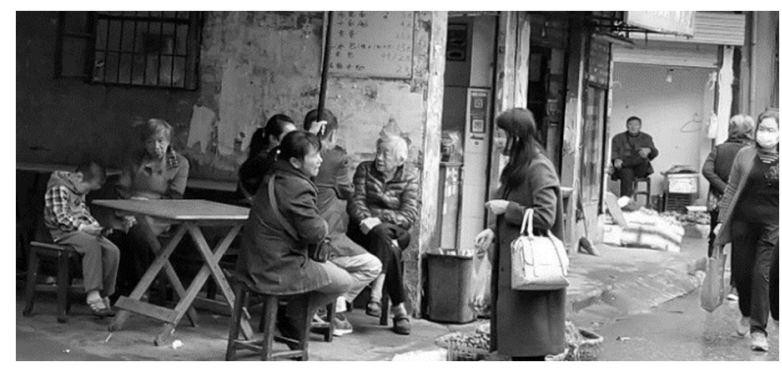

Fig.6. The teahouse

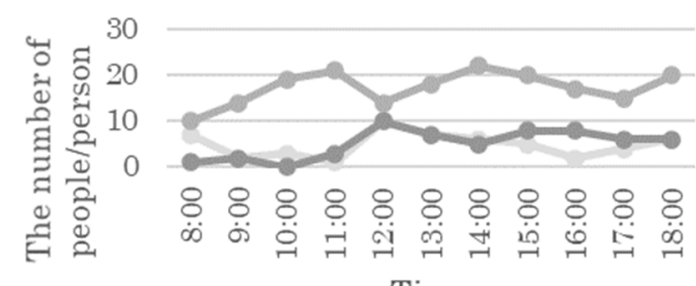

Time

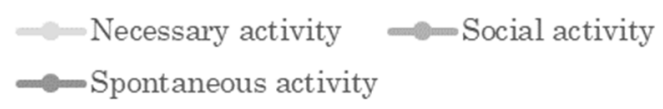

Fig.7. Characterization of the teahouse vitality

Here, the active subjects are middle-aged and elderly people. The group activities are mainly social activities such as chatting and playing chass, accompanied by consumption behaviors such as eating, drinking tea and buying cigarettes. The residence time is longer. (Figure 7)

This is a secondary street in the district with normal accessibility, and most people who gather here are internal residents. Semi-open Spaces provide a good place to come and go freely, shade and shelter from rain. The lack of landscape vegetation, fitness facilities and fun devices lead to the fix if the aging of the activity subjects. 


\subsubsection{Front yard: leisure time for retired people}

There are many two-story and multi-storey houses in the Deshengqiao block.. Some residents have shared front yards, which are between private and public Spaces. (Figure 8)

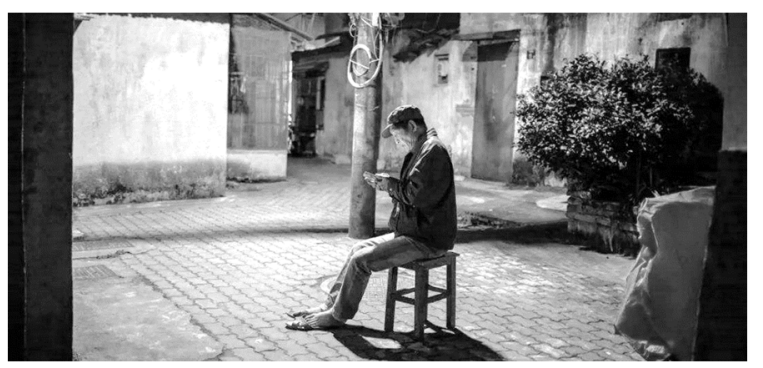

Fig.8. The front yard

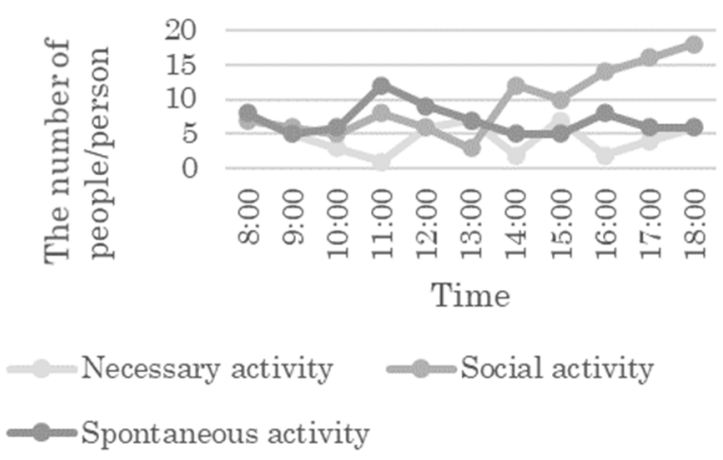

Fig.9. Characterization of the front yard vitality

The number of active subjects is significantly reduced and the residence time is longer. The activities of basking in the sun and reading newspapers are mainly for retired people. Occasionally there are drying, eating and other necessary activities. At about 18:00 in the evening, there is a phenomenon of the elderly gathering and dancing. (Figure 9)

This is a secondary street in the district with normal accessibility. The ground is $10 \mathrm{~cm}$ higher than the road with good safety, and the pavement is permeable bricks. But the lack of seating and awning for rest, pedestrians rarely stay, and the elderly need to bring their own chairs. The landscape is only old trees, lack of diversity and interest.

Zang Hui, a postgraduate student from Dalian University of Technology, wrote a paper "A research on the City square dynamic space element and design strategy", which mainly elaborated the principle of building vitality from three perspectives: human needs, material level and regional culture. To sum up, the land inside the Deshengqiao block is limited, and the space functions can only meet people's physiological needs and basic social needs. There is a great lack of basic surface design, spatial enclosure, public facilities and landscape art at the material level, and places with cultural and spiritual significance are more lack.

\subsection{The edge space reconstruction and the urban renewal}

With the highly homogenization of urban development, place spirit and place memory are disappearing. We can see the same landscape all over the country, the same "Changsha Stinky Tofu", "Shanghai Women's Snow Cream", "Cai Linji hot-and-dry noodles" business places.

Deshengqiao motled wooden door, public faucet, bamboo bed, handmade leather shoes, face market, old bath, boiling water room... Many things are disappearing, the feelings of the old street in people's hearts surging.

The team from Tsinghua University once built an interesting wall design at the Beixiaoqiang street, Taiyuan City, Shanxi Province. The combination of old objects and $3 \mathrm{D}$ paintings encourages people to recall the past years and forms a unique landscape of the old street, which has been praised by the majority. (Figure 10)

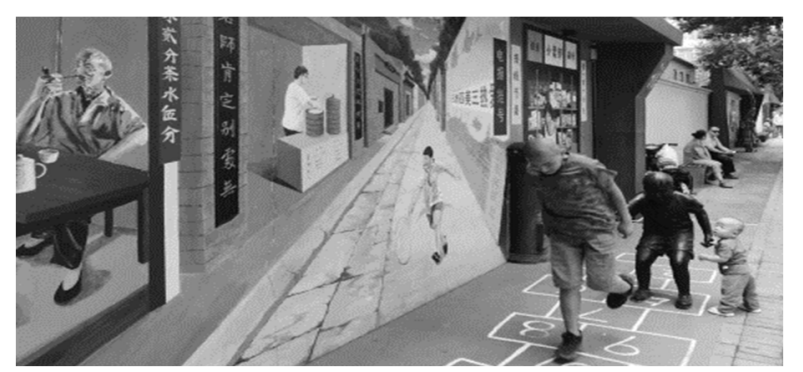

Fig.10. The nostalgic art design in Taiyuan

Perhaps the spirit of the Deshengqiao block is hiden in everyday objects and buildings. We hope to build a gathering place with strong local characteristics by means of micro-intervention, so as to improve the living quality of residents and integrate with the surrounding scenic spots.

It includes the following three steps:

\subsubsection{Restoring the ancient buildings along the street}

More than 10 buildings with a history of more than 70 years along the Deshengqiao street will be restored, while the rest of the buildings will be assessed for reinforcement and reconstruction.

\subsubsection{Transforming the entrance of the block to absorb the surrounding visitors}

The entrance node is transformed into a small entrance square, emphasizing that it can be stayed, viewed and spirituality. The street features of Deshengqiao will be externalized and fully incorporated into the surrounding tourists. (Figure 11) 


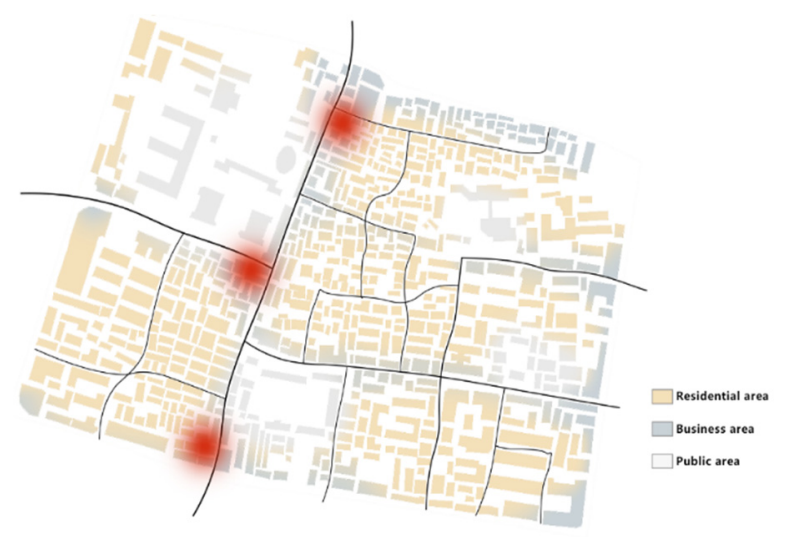

Fig.11. Selected points for the transformation of entrance space

\subsubsection{Divide the level of internal openness and construct new public space.}

We use spatial syntax to select some important spatial nodes, insert public space, construct new spiritual space and leisure places, and activate the site. (Figure 12-13)

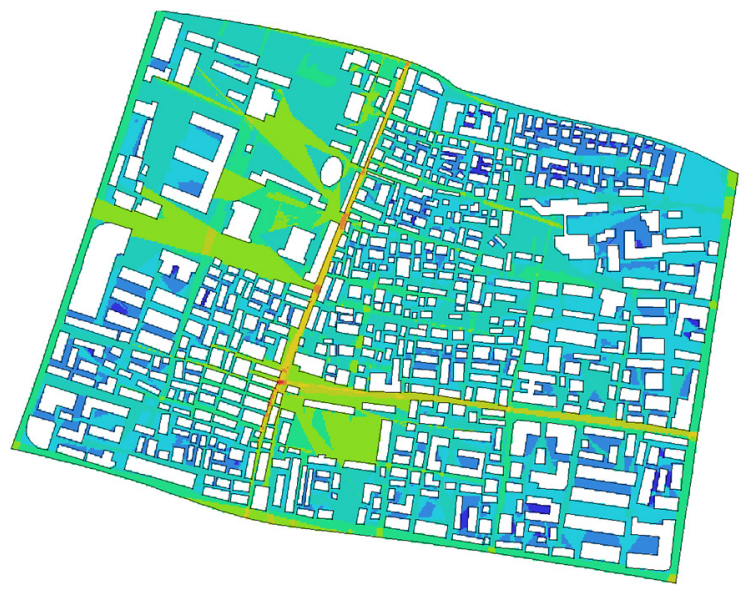

Fig.12. Visibility analysis by spatial syntax

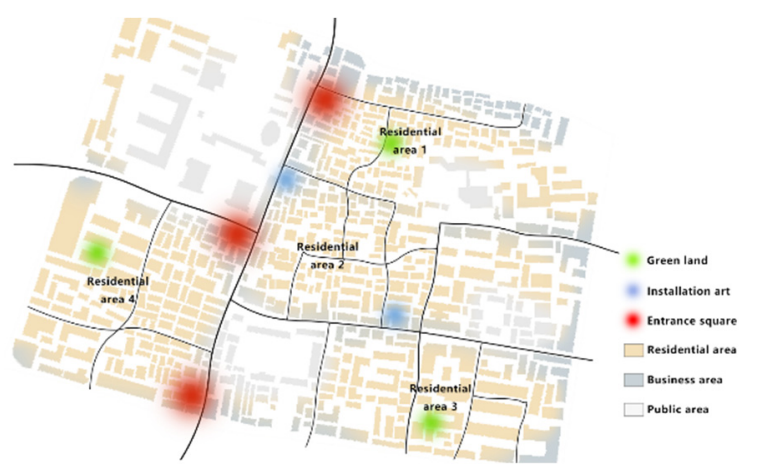

Fig.13. Residential group division and selected points for the transformation

The green space in front of the house is distributed in each residential area, and its location takes the location of chess \& card rooms and the location with poor visibility into account, which is conducive to improving the land utilization rate.

"Installation Art" presents the most distinctive and life-rich articles and buildings of the Deshengqiao block in artistic form, such as three-dimensional paintings, cultural walls and themed landscape pavilions, which are arranged in the edge space of the Deshengqiao block. With the ornament landscape afforestation, they can form the good spirit place, the communicating place and the leisure place. It can greatly improve residents' happiness and city image construction. (Figure 14)

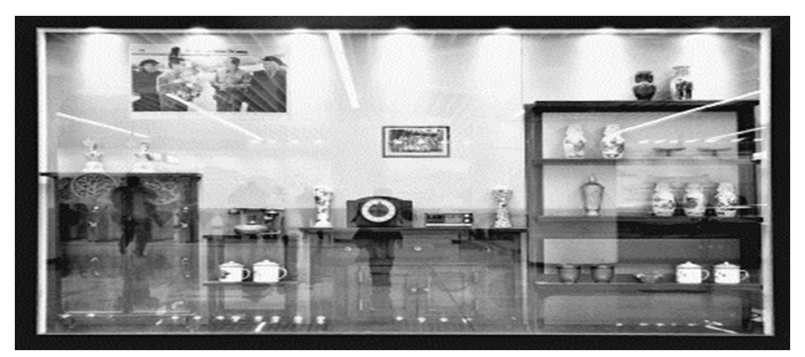

Fig.14. Deshengqiao culture and art installation

\section{Conclusion}

Based on the observation of the structure of the edge space of the Deshengqiao block and the records of residents' thoughts and activities, we draw the following conclusions:

- The Deshengqiao block is highly inclusive and open. Attractive street entrances should be created to help meet the need for openness.

- The Deshengqiao block has an extremely rich edge space and residents' activities, which is different from homogenized commerce or landscape. The spirit of "Wuhan" should be brought into full play during the reconstruction and renewal of the block. Create leisure and comfortable exchange place and spiritual space, with the principle of attraction and residence.

The cultural core of the Deshengqiao block is not classic historical buildings, but life itself. Compared with the homogenized landscape greenway and the homogenized commercial scenic spot, the original beauty of the city has the power to move people's hearts and commercial value. Urban reconstruction on the premise of preserving the characteristics of the historic district is helpful for tourists to feel the historical features of the old Wuchang, for residents of the Deshengqiao block to enjoy the achievements of modern civilization on the basis of retaining their inherent living habits, and for Wuhan people to keep their rural soul.

\section{References}

1. Hu Kai. Study on Human Activity and Interface Relationship in the Fringe Space of Historical Block $[\mathrm{J}]$. Building Materials and Decoration, 2018, No.551(42):75-76.

2. Kevin Lynch. Urban imagery. The 2nd edition [M]. Huaxia Publishing House, 2011.

3. C. Alexander, Alexander, et al. Architectural Pattern Language [M]. Intellectual Property Publishing House, 2002.

4. Chang Yalan, Xiao Bin, Chen Dongyan. Research on Landscape Design of Green Edge Space in Linear Park -- A Case Study of Xi 'an Ring City Xiyuan [J]. 
Journal of Northwest Forestry University, 2011,26(03):186-189.

5. XING Zhong, WANG Qi. On edge space [J]. New Architecture, 2005, 000(005):80-82.

6. Urban acupuncture and moxibustion [J]. Huazhong Architecture, 2012, 30(10):23-23.

7. Chen Wenjia, Zhu Chunyang. Study on the Relationship between Space and Behavior on the Edge of Urban Living Block [C]// Society of Chinese Landscape Architecture. 0.

8. Ge Liang, Ding Yuan, Research on Wuhan Hualin Historic and Cultural District-National Historical and Cultural City Research Center Historic Districts, Urban Planning, 2011 (10) : 102-103. 